\title{
NUMERICAL ANALYSIS OF RING FOOTINGS RESTING ON SAND BEDS
}

\author{
Mohamed M. A. Hussein* \\ Civil Eng. Departement, Faculty of Eng., Sohag University, Sohag, Egypt.
}

\begin{abstract}
Nowadays, more and more ring footings are used in practice specially for axi-symmetric structures. In this paper, a numerical analysis was performed using PLAXIS software for calculating bearing capacity factor $N_{\gamma}$ for rough circular and ring footings on sand. The analysis was carried out using Mohr-Coulomb's criterion for soil. The bearing capacity was calculated for rough circular and ring footings and then the bearing capacity factor $N_{\gamma}$ was calculated. The effect of different factors such as angle of internal friction of sand, $\varphi$, radius ratio $(n)$ and different external diameters of circular and ring footings $\left(D_{o}\right)$ were studied. The load settlement curves for circular and ring footings were compared, with emphasis on the ultimate bearing capacity. The analysis indicated that radius ratio has a significant effect on the ultimate bearing capacity of ring footings, were ultimate bearing capacity decreases with increasing radius ratio. However, little or no change in bearing capacity factor $N_{\gamma}$ was observed. Also, the results indicated that there is no significant effect of footing size $\left(D_{o}\right)$ on the bearing capacity factor $N_{\gamma}$ value. It is found that the space in ring footing $\left(D_{i}\right)$ has a significant effect on the change of failure mode of soil from both local and punching shear failure to a general shear failure for loose and medium sand, respectively. Also, the space in ring footing has a significant effect on the length and width of failure zone under ring footings.
\end{abstract}

(C) 2021 Published by Faculty of Engineering - Sohag University. DOI: 10.21608/SEJ.2021.155946.

Keywords: Sand; Ring Footings; Radius ratio; Bearing capacity; Failure mode.

\section{INTRODUCTION}

The bearing capacity and settlement for both strip and circular footings have already been one of the most highly interesting areas in geotechnical engineering for researchers and practical engineers. Defining the correct bearing capacity of the footing is a very important factor in economic terms. A lot of observations have been made in the literature in order to calculate the bearing capacity of strip, square, rectangular and circular footings using the limit equilibrium method [1,2]. In recent years, numerical methods, such as finite element method [3, 4] and the finite difference method [5, 6], have been widely used to compute the bearing capacity of strip and circular footings. Nowadays, more and more ring footings are used for axi-symmetric structures such as water tower structures, transmission towers, TV antennas, silos, chimneys, and storage tanks and so on. The use of ring footings decreases the amount of material used and is more economical. This has led to an increasing use of ring footings in countries which construction material is more expensive. Proposed different relations for prediction

\footnotetext{
* Corresponding author: mohamed.ma_2000@yahoo.com
} 
of the bearing capacity and settlement of strip, circular and square footings are not suitable for the ring footings. Therefore, the theoretical prediction of ultimate bearing capacity and settlement for ring footings is a requirement in the design. Solutions to calculate the elastic settlements of ring foundations are available in the literature [7, 8].

Some experiments have also been performed to compute the bearing capacity of ring footings $[9,10,11,12]$. Kumar and Ghosh [13] investigated the bearing capacity factor $N_{\gamma}$ for both smooth and rough ring footings by using the method of characteristics assuming that the interface friction angle between the footing base and the underlying soil mass increases gradually from zero along the footing center line to along the footing base. Hataf and Boushehrian [10] performed a series of laboratory tests on model ring footings and found that for radius ratio $(n)$, which is the ratio of internal radius $\left(r_{i}\right)$ to external radius $\left(r_{o}\right)$ equals to 0.4 the bearing capacity reaches its maximum for sand. Hataf and Razavi [11] found that radius ratio value for maximum bearing capacity of sand is not a unique value but is in the range of 0.2 to 0.4. Zhao and Wang [14] utilize a finite difference code FLAC to study bearing capacity factor $N_{\gamma}$ for ring footings in cohesionless soil. It was found that the value of $N_{\gamma}$ decreases significantly with the increase of radius ratio, the value of $N_{\gamma}$ for a rough ring footing, especially for larger values of friction angle, is obviously higher than that for a smooth footing. In this study, the bearing capacities of circular and ring footings with different parameters were studied.

\section{NUMERICAL MODELING}

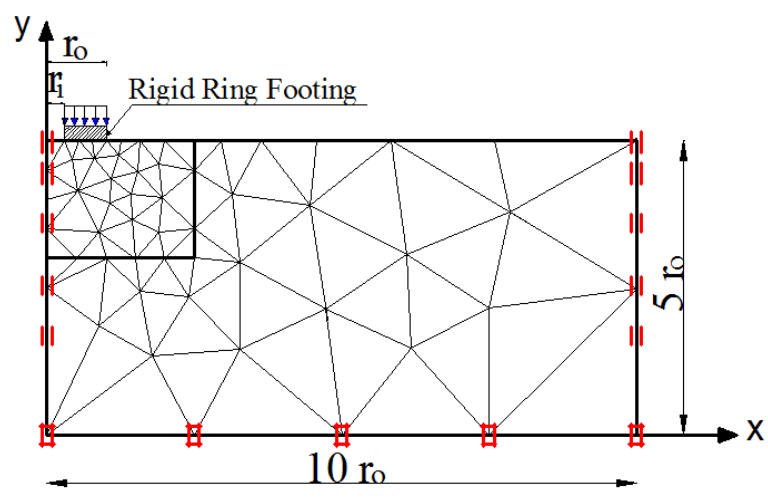

Fig. 1. Simulation of ring footing in the numerical analysis.

The numerical modeling is implemented using the commercial finite element software PLAXIS, developed by PLAXIS BV, Netherlands [15]. The numerical model used in this study is defined as shown in Fig. 1. The circular and ring footing is modeled as a rigid concrete material contact with underlain soil by an interface element.

The rigid ring footing is specified with external radius $r_{o}$ and internal radius $r_{i}$. The model footing was $0.5 \mathrm{~m}$ height and external radius $r_{o}$ varies from $1.0 \mathrm{~m}$ to $4.0 \mathrm{~m}$ and the radius ratio $(n)$ ranges from 0.0 to 0.75 as shown in table (2). The load was applied on the footing as a distributed load. The input values of distributed loads were given in force per unit area $\left(\mathrm{kN} / \mathrm{m}^{2}\right)$. Since the problem is axis-symmetric, only half of the problem domain is considered. The half domain is given a depth equals to 5 times of the external radius and extends 10 times the external radius from the centerline of ring footing to make the "boundary influence" on the estimation of the collapse load neglectable. The boundary conditions of the model were taken as follows (provided with standard fixity option in PLAXIS).

- At the left and right boundary of the soil model, $u_{x}=0.0, u_{y} \neq 0.0$

- At the bottom of the soil model, $u_{x}=u_{y}=0.0$.

The elements used in this study to present the soil and footing are isoperimetric triangular elements with 15 nodes which give much fine distribution of nodes and thus more accurate results than similar mesh computed of the same element with 6 nodes. PLAXIS code support a various model to simulate the mechanical behavior of soil. The model that was found to be adequate for this study is the Mohr-Coulomb model [16]. The Mohr- 
Coulomb model is one of the first soil behavior models which is elasto-plastic models. This model used five parameters which consist of elasticity modulus (E), Poisson's ratio $(v)$, internal friction angle of soil $(\varphi)$, cohesion (c) and dilation angle $(\psi)$. These used parameters in this study are shown in Table 1. A drained behavior is assumed for the materials for the bearing capacity calculations. Initial stresses in the soil are driven from the material weight $(\gamma)$. In PLAXIS software the horizontal stress in static state is calculated using Jacky's formula [16].

$$
K_{o}=1-\sin \phi
$$

TABLE 1. SOIL PROPERTIES USED IN NUMERICAL ANALYSIS.

\begin{tabular}{|c|c|c|c|c|}
\hline$\overline{\varphi\left(\left(^{\circ}\right)\right.}$ & $\bar{E}\left(\mathrm{kN} / \mathrm{m}^{2}\right)$ & 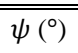 & $\gamma_{\text {dry }}\left(\mathrm{kN} / \mathrm{m}^{3}\right)$ & $\gamma_{\text {sat }}\left(\mathrm{kN} / \mathrm{m}^{3}\right)$ \\
\hline 40 & \multirow{7}{*}{$6.4 \times 10^{4}$} & 10.0 & 17.44 & 17.44 \\
\hline 35 & & 5.0 & 16.84 & 16.84 \\
\hline 30 & & 0.0 & 16.24 & 16.24 \\
\hline 25 & & 0.0 & 15.66 & 15.66 \\
\hline 20 & & 0.0 & 15.07 & 15.07 \\
\hline 15 & & 0.0 & 14.48 & 14.48 \\
\hline 10 & & 0.0 & 14.00 & 14.00 \\
\hline
\end{tabular}

There are many suggested equations by previous research to calculate the dialation angle of sand. From these equations, PLAXIS's equation [1].

$$
\psi=\phi-30^{\circ}
$$

where the calculation of settlement under ring footings is out of this study, so the elastic modulus $(E)$ for different soil densities was taken constant and equal to $6.4 \times 10^{4} \mathrm{kN} / \mathrm{m}^{2}$ [1]. The unit weight $(\gamma)$ for different sand densities was taken as a function of internal friction angle $(\varphi)$ from the following equation [1].

$$
\phi=8.5 \gamma-108.1
$$

To obtain accurate results from the numerical analysis, the finite element mesh size, the number, and the distribution of element are chosen to satisfy both of the following two requirements [1].

- The expected shape of failure soil surface should be obtained.

\begin{tabular}{|c|c|c|c|c|c|c|}
\hline Group & Sub-group & $\varphi\left(^{\circ}\right)$ & $r_{o}(\mathrm{~m})$ & $\mathrm{n}=r_{i} / r_{o}$ & Symbols on Curves & Definition \\
\hline \multirow{7}{*}{ A } & A1 & 40 & \multirow{7}{*}{2.0} & \multirow{10}{*}{$\begin{array}{c}0.0,0.15, \\
0.30,0.45, \\
0.60,0.75\end{array}$} & $\mathrm{CF}$ & $\mathrm{n}=0.00$ \\
\hline & A2 & 35 & & & TF & $\mathrm{n}=0.15$ \\
\hline & A3 & 30 & & & SF & $\mathrm{n}=0.30$ \\
\hline & A4 & 25 & & & $\mathrm{NF}$ & $\mathrm{n}=0.45$ \\
\hline & A5 & 20 & & & OHT & $\mathrm{n}=0.60$ \\
\hline & A6 & 15 & & & OHF & $\mathrm{n}=0.75$ \\
\hline & A7 & 10 & & & & \\
\hline \multirow{3}{*}{ B } & B1 & \multirow{3}{*}{35} & 1.0 & & & \\
\hline & B2 & & 3.0 & & & \\
\hline & B3 & & 4.0 & & & \\
\hline
\end{tabular}

- A sensitivity study should be carried out for each test to obtain the best results.

TABLE 2. NUMERICAL STUDY PROGRAM. 


\section{CALCULATION OF BEARING CAPACITY FACTOR, $\boldsymbol{N}_{\gamma}$}

When the ground is loaded with a uniform surcharge pressure (q), according to Terzaghi's formula [17], the bearing capacity of a shallow strip footing can be obtained from:

$$
q_{u}=C N_{C}+q N_{q}+0.5 \gamma B N_{\gamma}
$$

where $C$ is the cohesion, $q$ is the equivalent surcharge, $\gamma$ is the unit weight, $B$ is the footing width, $N_{c}, N_{q}$ and $N_{\gamma}$ are the bearing capacity factors, which are dependent solely on the friction angle. For axially loaded circular footings, which has a diameter of $D_{o}$ and rests on the surface of the cohesionless soil ( $\mathrm{C}=0$ and no surcharge) with a unit weight, $\gamma$.

Erickson and Drescher [9] proposed the generalized bearing capacity formula as follows: -

$$
q_{u}=0.5 F_{\gamma s} \gamma D_{o} N_{\gamma}
$$

where $F_{\gamma s}$ is the factor accounting for the shape of footings.

In the literature, these are expressions and tables for the bearing capacity and shape factor $[1,2,16]$ but the characteristics of most these are almost the same. According to Erickson and Dresher's proposal [9], the shape factor can be considered to modify the bearing capacity factors by $\bar{N}_{\gamma}=F_{\gamma s} . N_{\gamma}$, for strip footings, $\bar{N}_{\gamma}=N_{\gamma}$. However, for the ring footings, the bearing capacity factors depend not only on the frictional angle $\boldsymbol{\varphi}$ but also on the radius ratio, $n$. In order to compute the value of $\bar{N}_{\gamma}$ for cohesionless soil with no surcharge, the following formula can be used:

$$
\begin{aligned}
& q_{u}=0.5 \gamma\left(D_{o}-D_{i}\right) \bar{N}_{\gamma} \\
& \bar{N}_{\gamma}=\frac{q_{u}}{0.5 \gamma\left(D_{o}-D_{i}\right)}=\frac{q_{u}}{\gamma\left(r_{o}-r_{i}\right)}
\end{aligned}
$$

where $D_{o}, D_{i}$ are external and internal diameter of ring footing, respectively, $r_{o}$ and $r_{i}$ are external and internal radius, respectively.

\section{RESULTS OF NUMERICAL STUDY AND DISCUSSION}

Load-settlement curves for different values of radius ratio $n=0.0,0.15,0.3,0.45,0.6$ and 0.75 for $\varphi$ ranges from $40^{\circ}$ to $10^{\circ}$ and $r_{o}=2.0 \mathrm{~m}$ (Group A) are shown in Figs. 2(a), (b), (c), (d), (e), (f), and (g). From these figures it can be concluded the following: -

1. The value of ultimate load decreases with increasing the radius ratio for all study cases.

2. For circular footings, the failure mode is dependent on the soil friction angle. For dense soil $\varphi=35^{\circ}$ to $40^{\circ}$, the failure mode of soil is a general shear failure. For medium dense sand $\left(\varphi=30^{\circ}, 25^{\circ}, 20^{\circ}\right)$ the failure mode is a local shear failure, for loose sand the failure mode is a punching shear failure. These results are in an agree with the previous literature $[1,2,16]$.

3. For ring footings the failure mode is dependent on the soil friction angle and radius ratio. In all study cases the failure mode under ring footings is a general shear failure, it means that for ring footings on medium and loose cohesionless soil, the failure mode changes from local, punching shear failure to a general shear failure. This result can be due to that the ring footing ensures better enclosibility of the soil inside the space of the footing by preventing the soil from flowing outward. it can be applied particularly when the soil is medium or loose. 


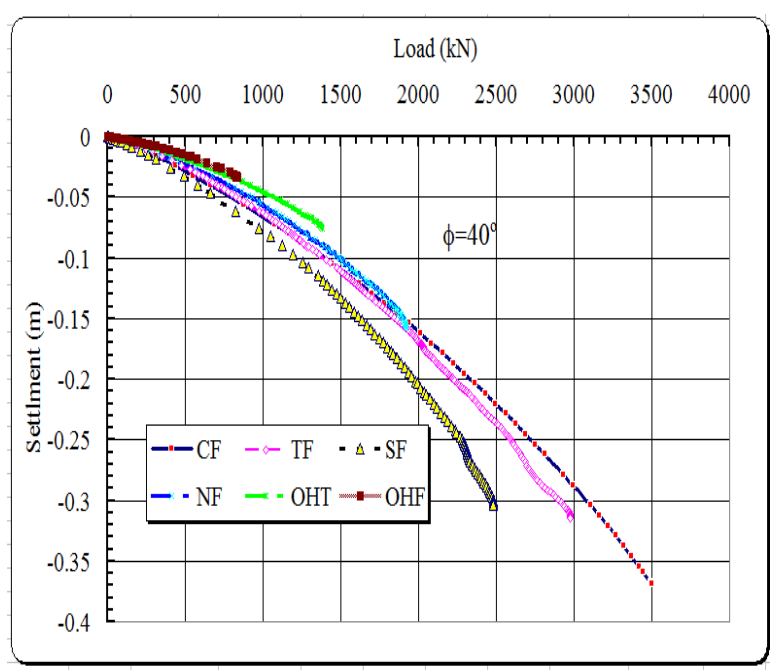

(a) $\phi=40^{\circ}$

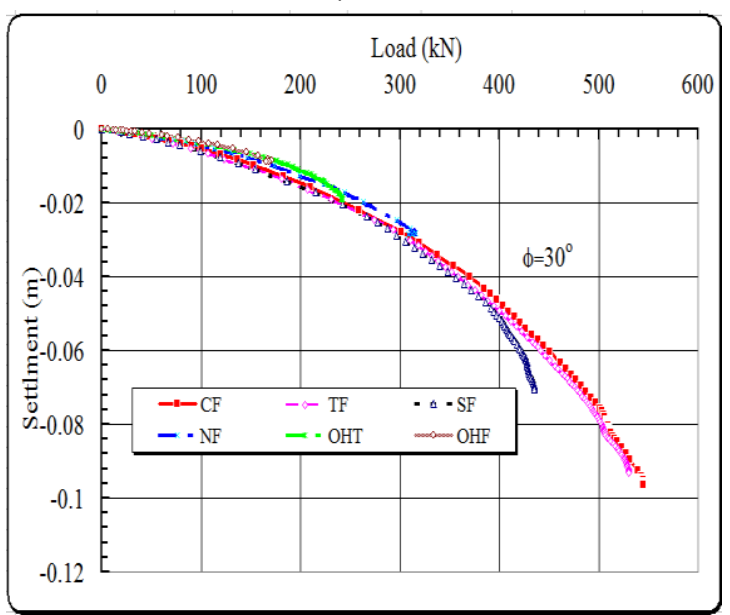

(c) $\phi=30^{\circ}$

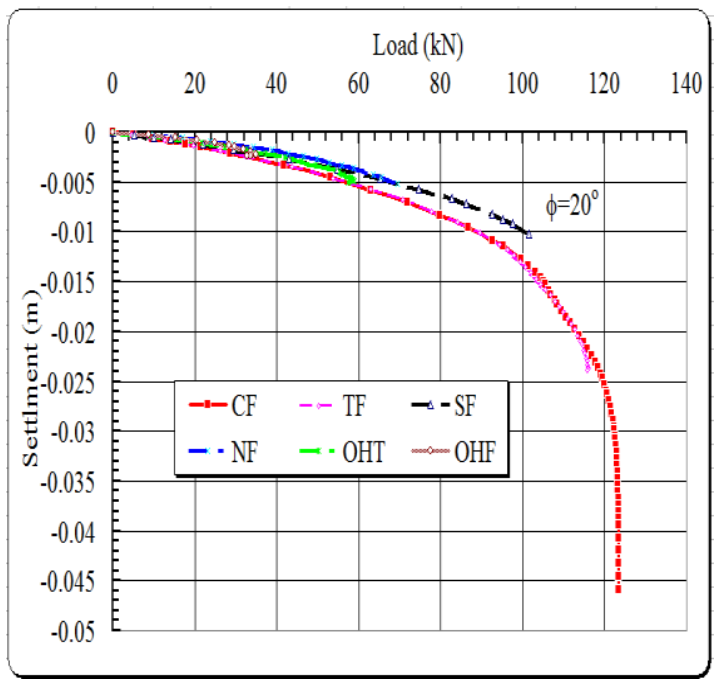

(e) $\phi=20^{\circ}$

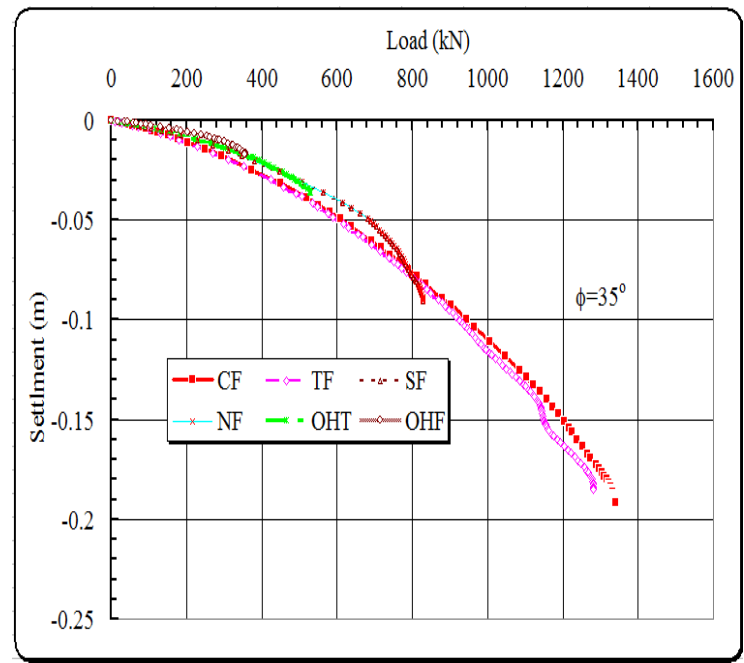

(b) $\phi=35^{\circ}$

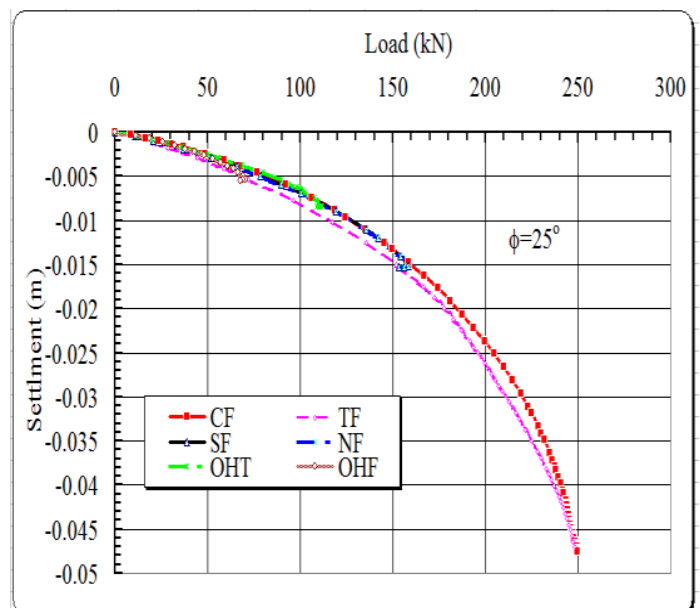

(d) $\phi=25^{\circ}$

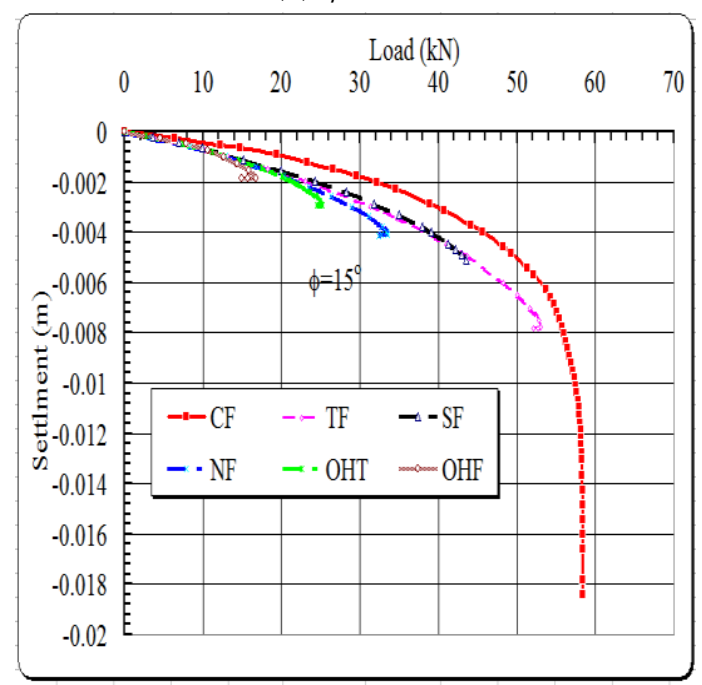

(f) $\phi=15^{\circ}$ 


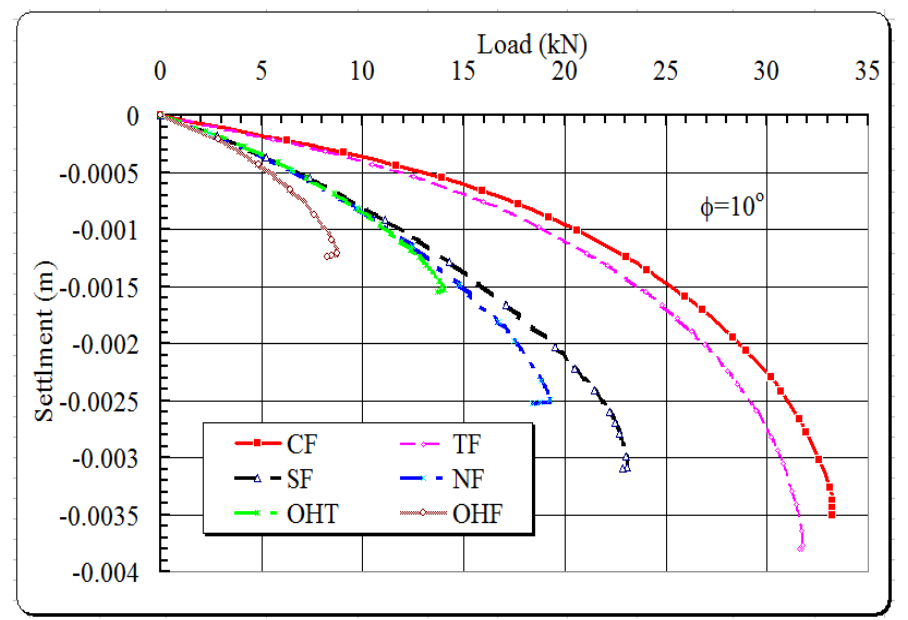

(g) $\phi=10^{\circ}$

Fig. 2. Load-Settlement Relationship for Different Radius Ratio.

\subsection{Effect of internal friction angle of sand on the load/settlement behavior}

Load-settlement curves for different values of internal friction angle ranges from $10^{\circ}$ to $40^{\circ}$ with increment $5^{\circ}$ and radius ratio $(n)$ ranges from 0.00 to 0.75 with increment of 0.15 are drawn as shown in Figs. 3(a), (b), (c), (d), (e), (f), and (g). From these figures it can be concluded the following:

- As expected, the ultimate bearing capacity for circular and ring footings increases with increasing the internal friction angle of sand bed.

- The rate of increasing the ultimate bearing capacity for circular footings are nearly the same for ring footings.

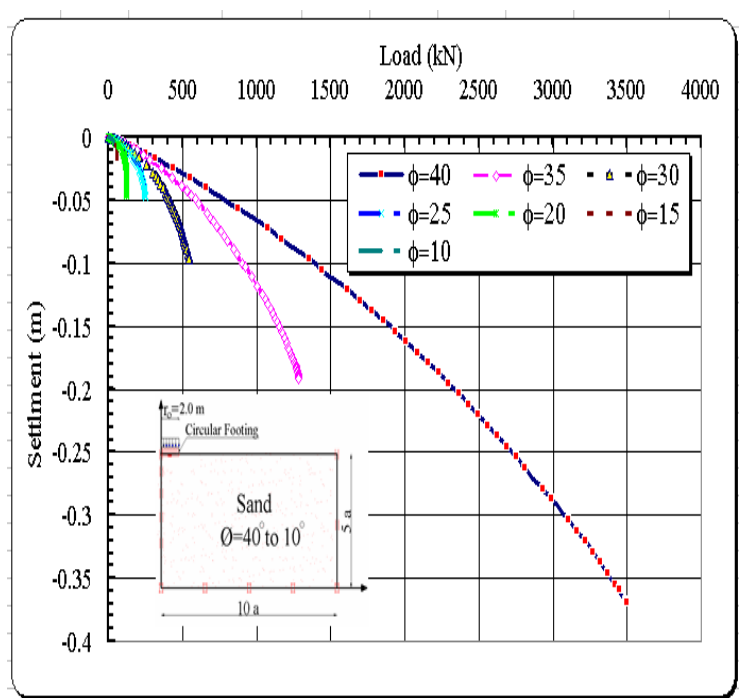

(a) $n=0.0$

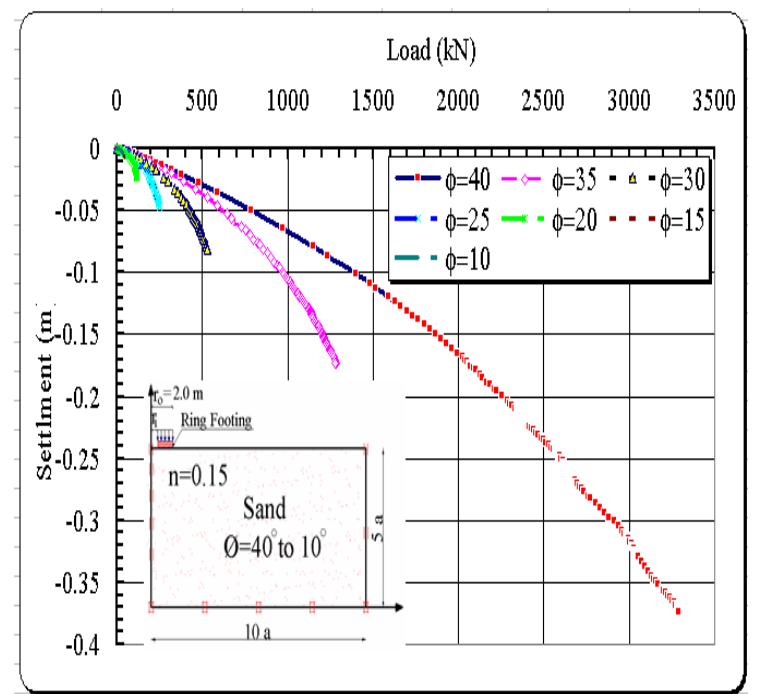

(b) $\mathrm{n}=0.15$ 


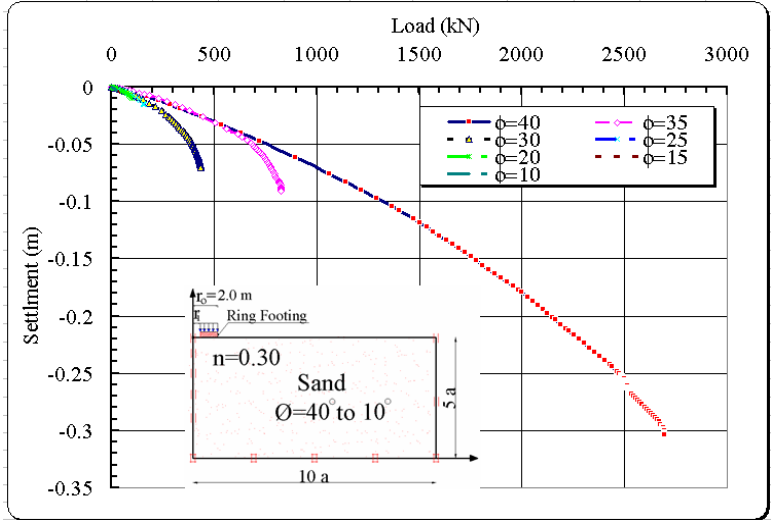

(c) $\mathrm{n}=0.3$

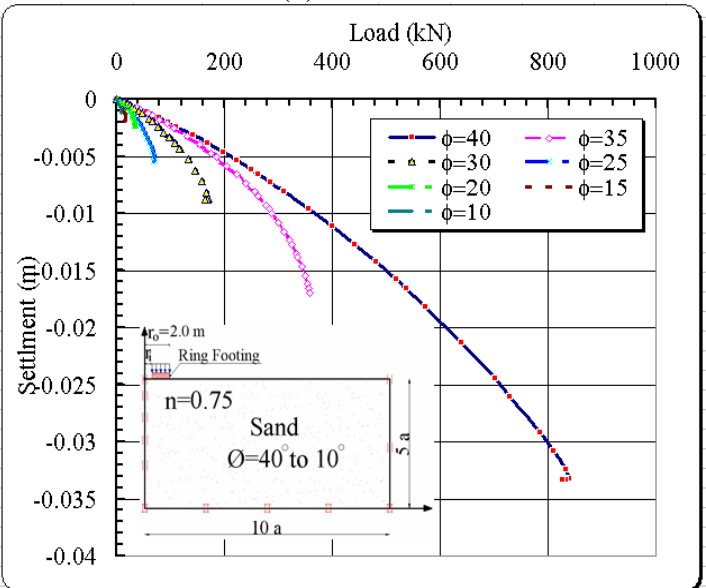

(e) $n=0.60$

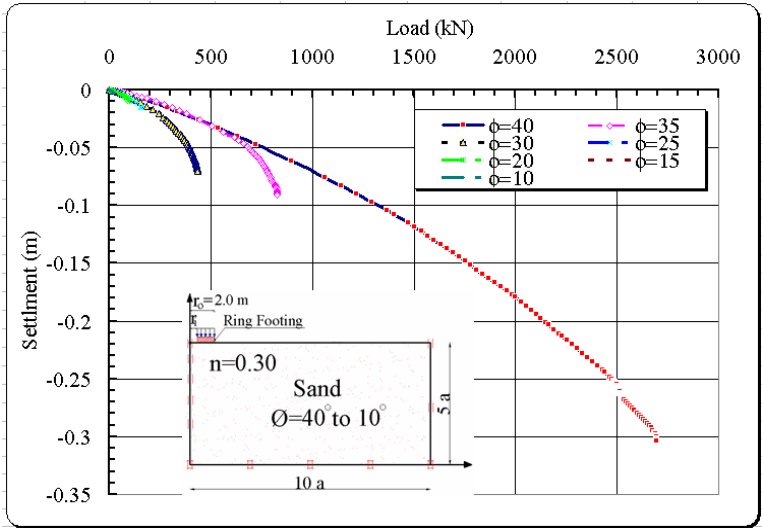

(d) $n=0.45$

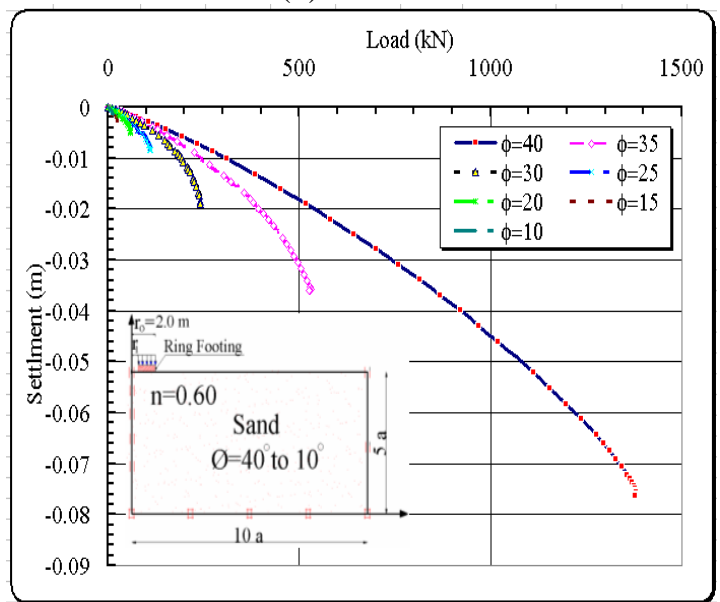

(f) $n=0.75$

Fig. 3. Load-settlement relationship for different friction angle of sand bed.

\subsection{Effect of radius ratio on $\bar{N}_{\gamma}$ value}

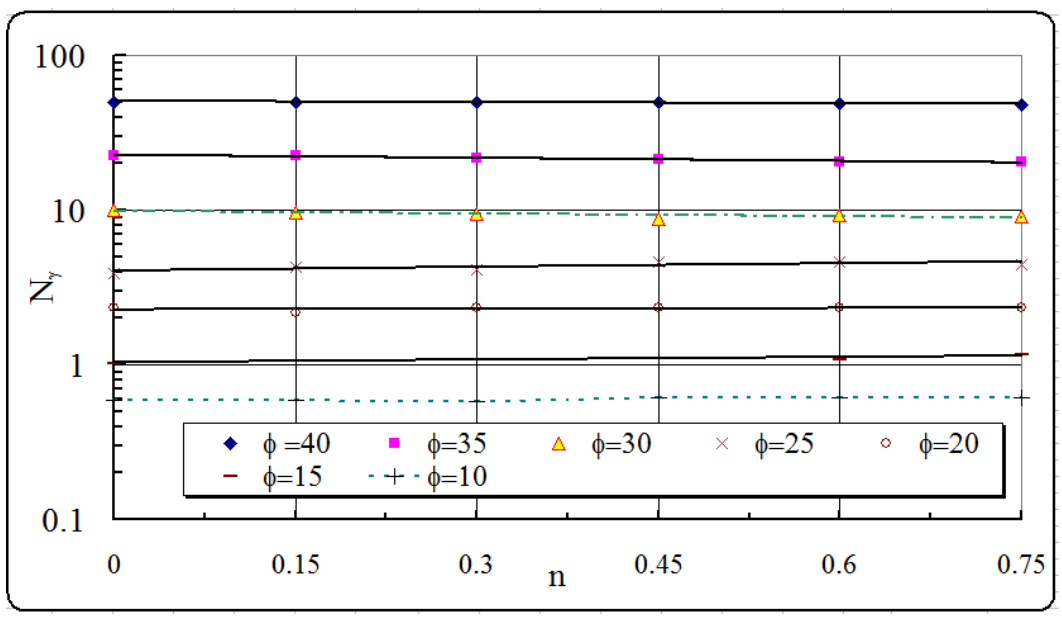

Fig. 4. Variation of $\bar{N}_{\gamma}$ value with radius ratio for different internal friction angle. 
The relationship between $\bar{N}_{\gamma}$ value (on log scale) and radius ratio (on ordinary scale) are shown in Fig. (4). From this Fig. it can be concluded that there is a little or no significant change in bearing capacity factor $\bar{N}_{\gamma}$ with different values of radius ratio (n), this means that the value of $\bar{N}_{\gamma}$ for different internal friction angle of sand bed $(\varphi)$ and different radius ratio can be determined from the literature values of $N_{\gamma}$ given by different researches for circular footings $[1,20]$ after taking into consideration the corrected value of $\bar{N}_{\gamma}$ as given in Eq. (5)

\subsection{Effect of circular and ring footing sizes on $\bar{N}_{\gamma}$ values}

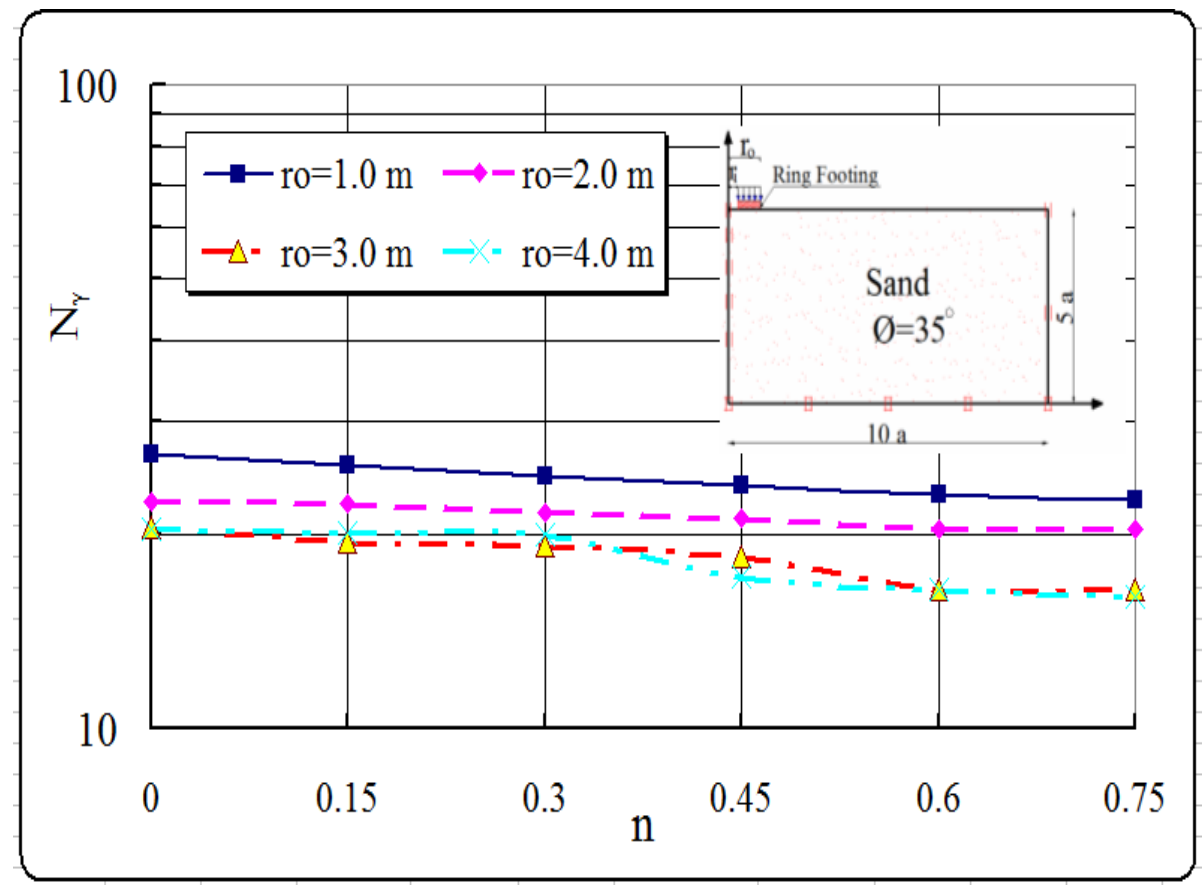

Fig. 5. Variation of $\bar{N}_{\gamma}$ value with radius ratio for different ring footing sizes

The relationship between $\bar{N}_{\gamma}$ value and radius ratio (n) for different external ring footings diameter $\left(D_{o}=2 r_{o}\right)$ are shown in Fig. 5. From this figure, it can be seen that the value of $\bar{N}_{\gamma}$ increases with decreasing the footing size $D_{o}$. In general, a radius ratio has a small effect on $\bar{N}_{\gamma}$ value.

\subsection{Comparison of $\bar{N}_{\gamma}$ value for ring footings}

The value of $\bar{N}_{\gamma}$ for both circular and ring footings with a rough base is compared with those computed by Zhao and Wange [14], Kumar and Ghosh [13] and is shown in Table 3 and Fig. 6. The results indicate that: -

1. The value of $\bar{N}_{\gamma}$ obtained in the present study for circular and ring footings is close to that calculated by Kumar and Ghosh [13], especially for loose sand $\left(\phi=10^{\circ}, 20^{\circ}\right)$.

2. The value of $\bar{N}_{\gamma}$ obtained in the present study for circular footing is close to that calculated by Kumar and Ghosh [13] and is lower than that obtained by Zhao and Wange [14] for medium dense sand $\left(\varphi=30^{\circ}\right)$.

3. The trend of $\bar{N}_{\gamma}$ with radius ratio (n) for ring footings is agree well with that obtained by Kumar and Ghosh [13]. 


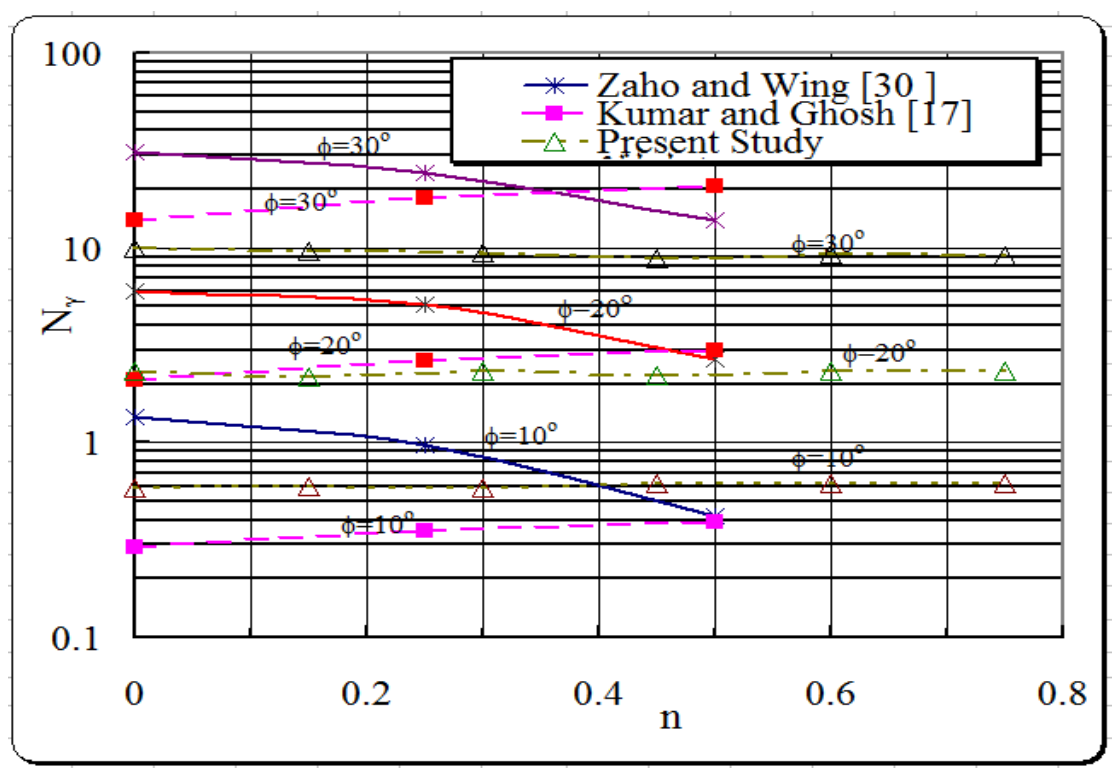

Fig. 6. Comparison of $\bar{N}_{\gamma}$ value with published results for circular and ring footings.

TABLE 3. COMPARISON OF $\bar{N}_{\gamma}$ VALUE FOR CIRCULAR AND RING FOOTINGS.

\begin{tabular}{|c|c|c|c|c|c|c|c|}
\hline \multirow{3}{*}{$\varphi$} & \multirow{3}{*}{$n$} & \multicolumn{6}{|c|}{$\overline{\bar{N}_{\gamma}}$} \\
\hline & & \multirow[b]{2}{*}{$\begin{array}{c}\text { Present } \\
\text { Study }\end{array}$} & \multirow{2}{*}{$\begin{array}{c}\text { Zhao \& } \\
\text { Wange [14] }\end{array}$} & \multicolumn{4}{|c|}{ Kumar and Ghosh [17] } \\
\hline & & & & $\delta^{\dagger}=\varphi\left(r_{i} / r_{o}\right)^{2}$ & $\delta=\varphi\left(r_{i} / r_{o}\right)$ & $\delta=\varphi\left(r_{i} / r_{o}\right)^{1 / 2}$ & $\begin{array}{c}\bar{N}_{\gamma} \\
\text { (average) }\end{array}$ \\
\hline \multirow{6}{*}{10} & 0.00 & 0.59 & 1.35 & 0.27 & 0.29 & 0.31 & 0.29 \\
\hline & 0.15 & 0.59 & - & - & - & - & - \\
\hline & 0.25 & - & 0.97 & 0.33 & 0.35 & 0.37 & 0.35 \\
\hline & 0.30 & 0.58 & - & - & - & - & - \\
\hline & 0.45 & 0.62 & - & - & - & - & - \\
\hline & 0.50 & - & 0.42 & 0.33 & 0.40 & 0.40 & 0.376 \\
\hline \multirow{6}{*}{20} & 0.00 & 2.32 & 5.98 & 1.96 & 2.2 & - & 2.08 \\
\hline & 0.15 & 2.19 & - & - & - & - & - \\
\hline & 0.25 & - & 5.11 & 2.36 & 2.67 & 2.87 & 2.63 \\
\hline & 0.30 & 2.32 & - & - & - & - & - \\
\hline & 0.45 & 2.32 & - & - & - & - & - \\
\hline & 0.50 & - & 2.67 & 2.74 & 3.02 & 3.16 & 2.97 \\
\hline \multirow{6}{*}{30} & 0.00 & 9.97 & 30.76 & 12.79 & 14.99 & - & 13.89 \\
\hline & 0.15 & 9.96 & - & - & - & - & - \\
\hline & 0.25 & - & 24.13 & 15.56 & 18.84 & 21.28 & 18.56 \\
\hline & 0.30 & 9.51 & - & - & - & - & - \\
\hline & 0.45 & 8.82 & - & - & - & - & - \\
\hline & 0.50 & - & 13.86 & 18.42 & 21.28 & 22.92 & 20.87 \\
\hline
\end{tabular}




\subsection{Effect of Radius Ratio on the Extent of Failure Surface}

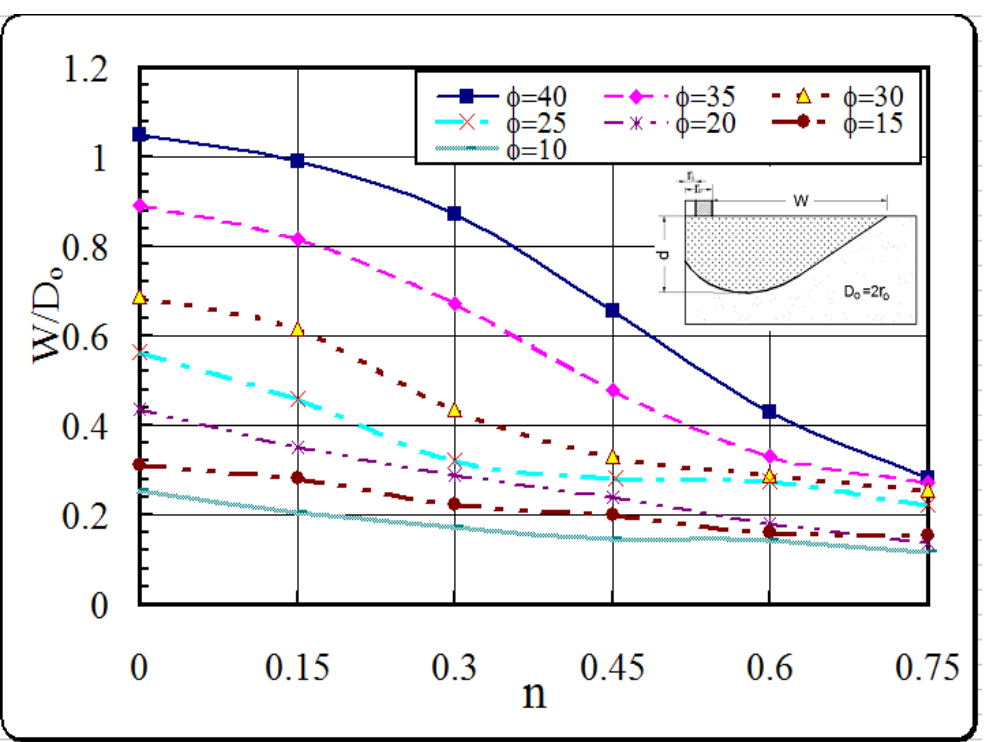

Fig. 7. Variation of maximum extent of failure surface with radius ratio.

The failure surface describes the geometry of the soil mass mobilized along a slip surface at the moment of incipient failure. A slip surface defines a velocity discontinuity and contains the soil mass that experiences uncounted plastic flow while the soil outside the slip surface remains at rest. Some widely used methods of analysis like limit equilibrium requires making a guess on the shape and geometry of the most critical failure surface a prior. In most cases the selection of the failure mechanism strongly influences the quality of the solution. The importance of analytical approaches, like finite element method and finite element-based limit analysis do not require an initial (user-defined) assumption on the geometry of the failure surface. The relationship between maximum extent of failure surface $\left(W / D_{o}\right)$ and radius ratio are plotted as shown in Fig. 7. From this Figure, it is important to note the following:

1. The lateral extent ratio $\left(W / D_{o}\right)$ decreases with increasing radius ratio for different internal friction angle of sand bed.

2.The lateral extent ratio $\left(W / D_{o}\right)$ of influence of circular and ring footings with different radius ratio $(n)$ and different internal friction angle $(\varphi)$ are determined in the form of equation as the following:

$$
W / D_{o}=0.165 e^{[(2.5-1.7 n) \tan \varphi-0.6 n]}
$$

The resulted curves from Eq. (8) are plotted as shown in Fig. 8.

A certain practical information can be drawn from the suggested equation:

a) Many questions arise during excavation near existing circular and ring footings as to the effect of soil removal on bearing capacity. Reductions in bearing capacity can be estimated by considering effects of removal within these zones. The lateral extent of this theoretical zone $\left(W / D_{o}\right)$ is also useful in determining effects of ground irregularities on footing capacity or the effects of footing loads on adjacent facilities.

b) The interfering between adjacent circular or ring footings should be considered according to Eq. (8). If the actual distance is less than the calculated, then the interaction effect on the bearing capacity should be taken into consideration.

c) Also, the side rupture distance ratio $\left(W / D_{o}\right)$ is useful in determining the required ground area to be considered in both experimental study (dimensions of used tank) and the finite element model. 


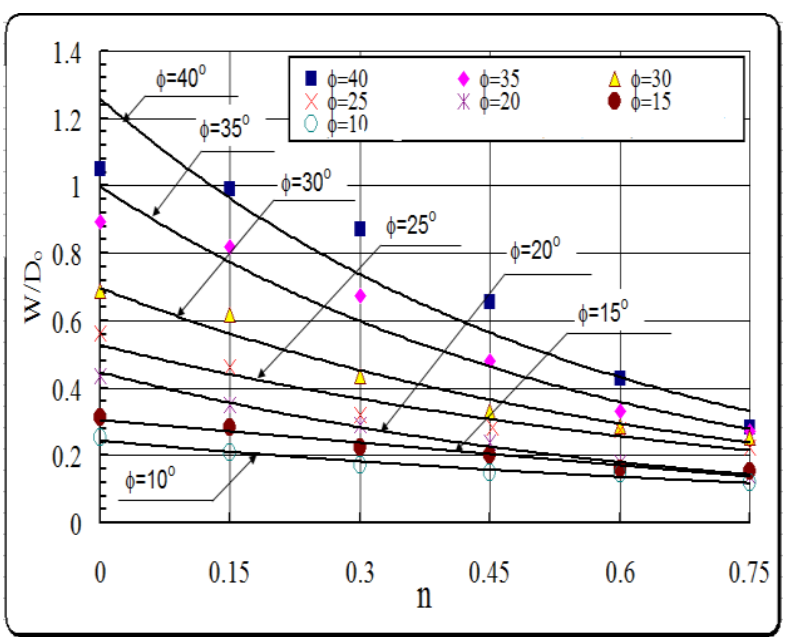

Fig. 8. Variation of maximum extent of failure surface with radius ratio as suggested formula Eq. (8).

\subsection{Effect of Radius Ratio on the Depth of Failure Surface}

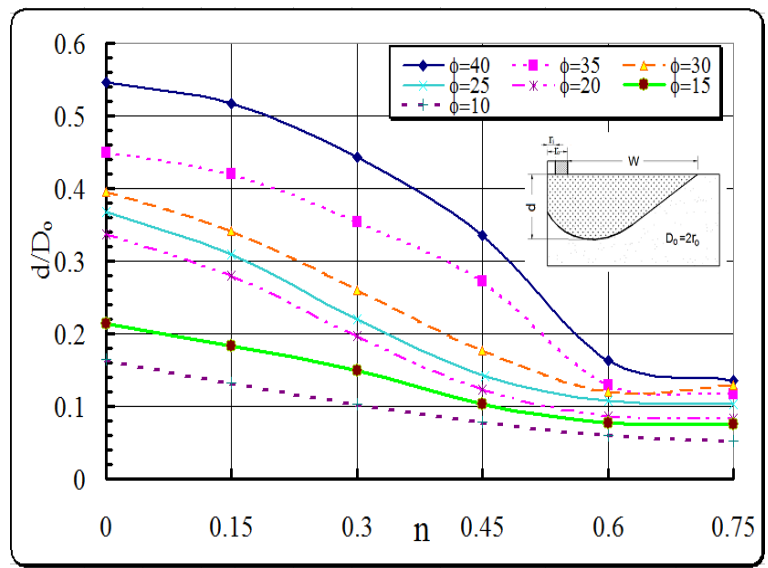

Fig. 9. Variation of maximum depth of failure surface with radius ratio.

The relationship between maximum depth of failure surface $\left(d / D_{o}\right)$ and radius ratio are plotted as shown in Fig. 9. From this figure, it is interesting to note the following.

1. The depth of failure surface under ring footings decreases with the increase of radius ratio for different internal friction angle.

2. The bearing capacity of circular and ring footings is dependent on the strength of soil within a certain depth ratio $\left(d / D_{o}\right)$ below the footing. Therefore, representative soil samples and frequent penetration test values must be obtained in this zone.

3. Any variations of soil properties through the maximum depth of shear zone should be taken into consideration when determining the bearing capacity and settlement.

4. The failure surface depth ratio $\left(d / D_{o}\right)$ of influence of circular and ring footings with different radius ratio $(n)$ and different internal friction angle $(\varphi)$ is determined in the form of equation as the following:

$$
d / D_{o}=0.14 e^{[(2-0.65 n) \tan \varphi-1.6 n]}
$$

The resulted curves from Eq. (9) are plotted as shown in Fig. 10. 


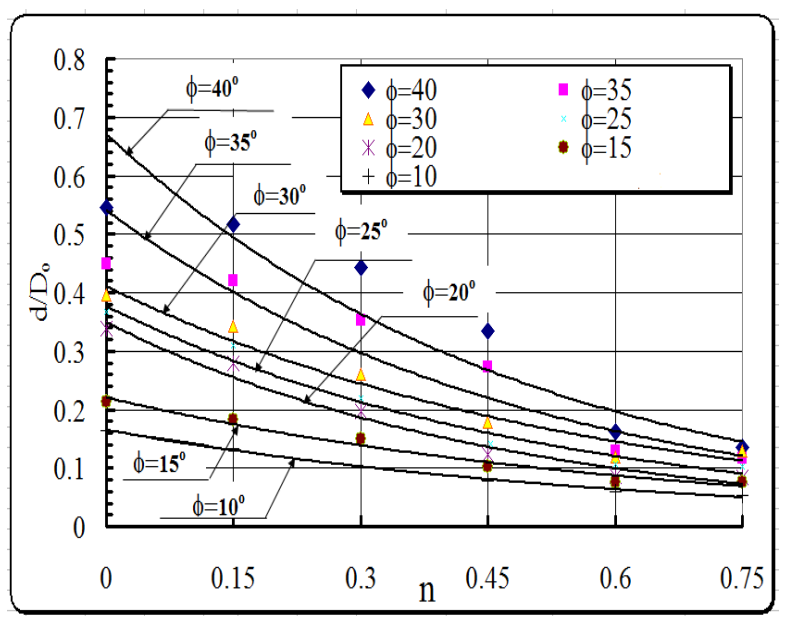

Fig. 10. Variation of maximum depth of failure surface with radius ratio as suggested formula Eq. (9).

\subsection{Effect of Radius Ratio on the Shear Zone Geometry}

The most important result obtained and related to the present study is the effect of radius ratio on the shear zone geometry. It is observed that both depth ratio $\left(d / D_{o}\right)$ and lateral extent ratio $\left(W / D_{o}\right)$ decrease with increasing radius ratio, as shown in Fig. 11.

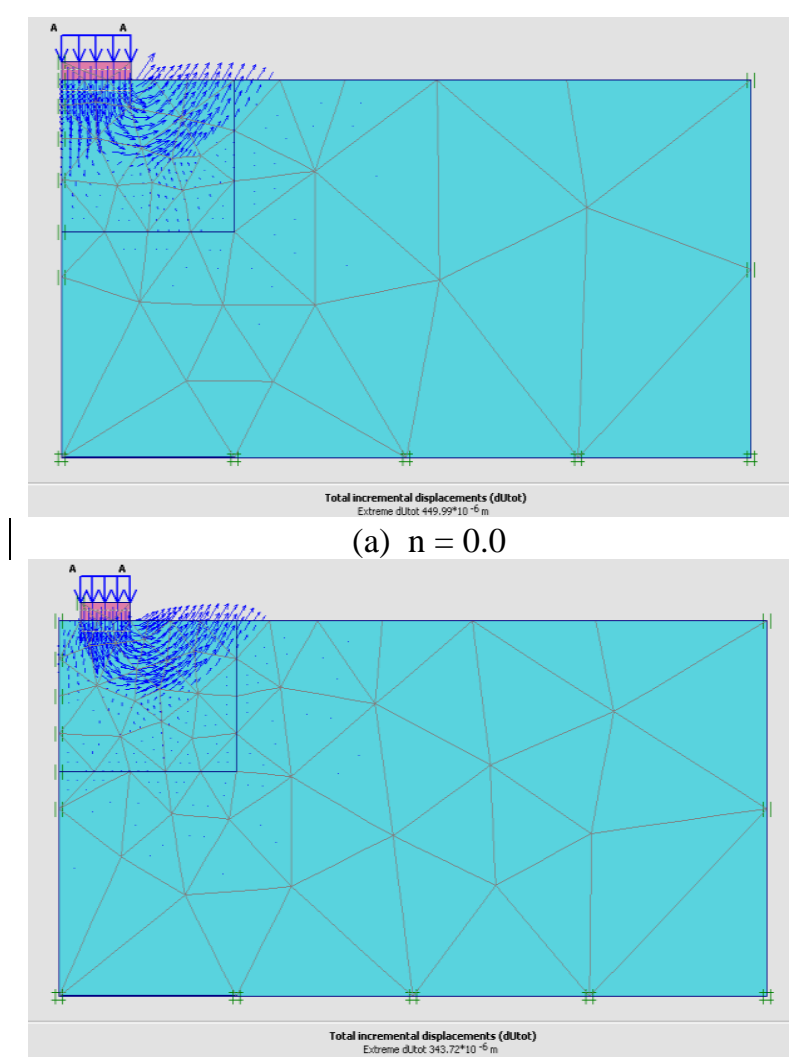

(c) $\mathrm{n}=0.30$

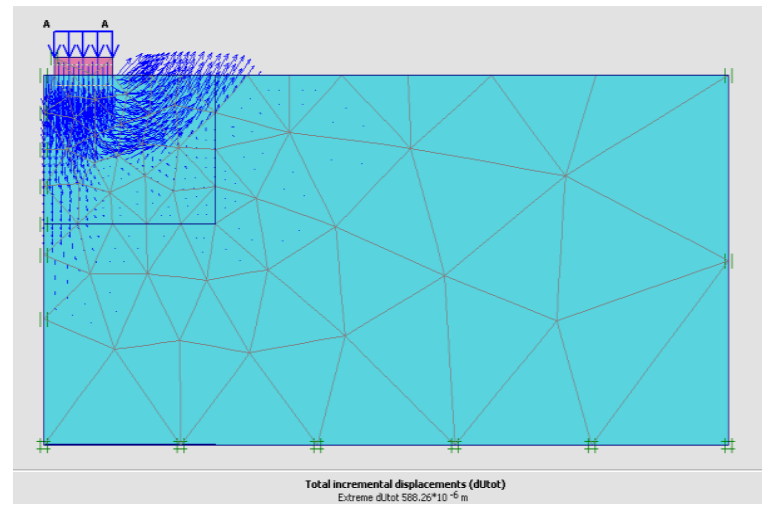

(b) $\mathrm{n}=0.15$

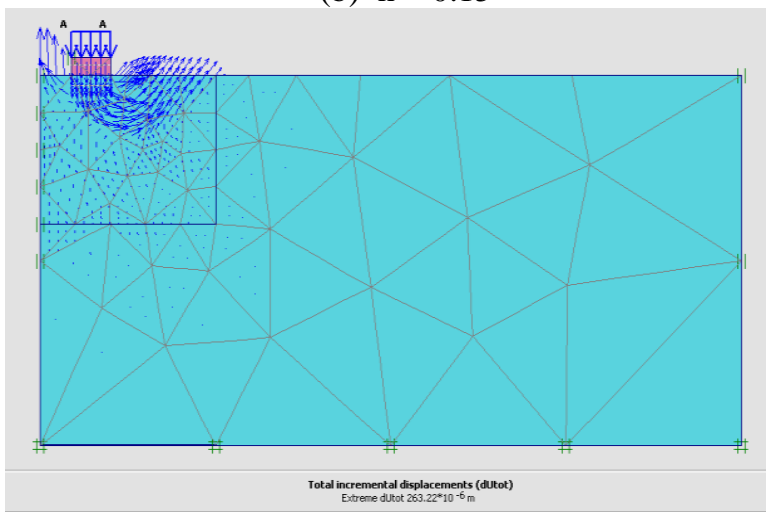

(d) $n=0.45$ 


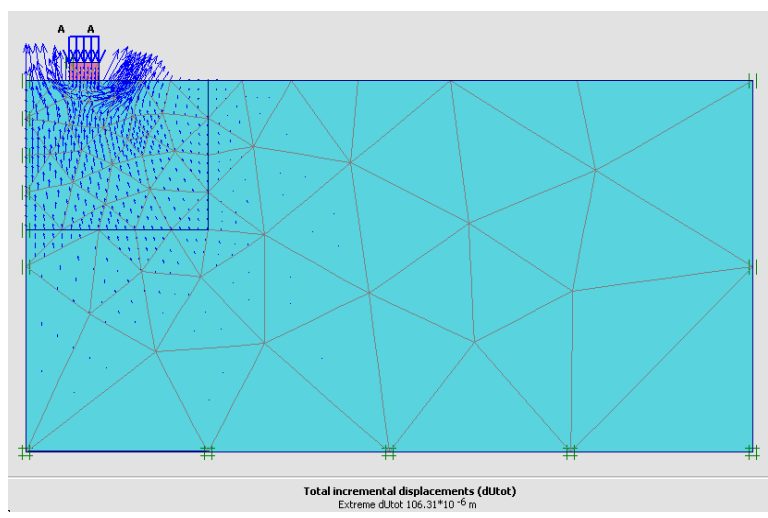

(e) $\mathrm{n}=0.60$

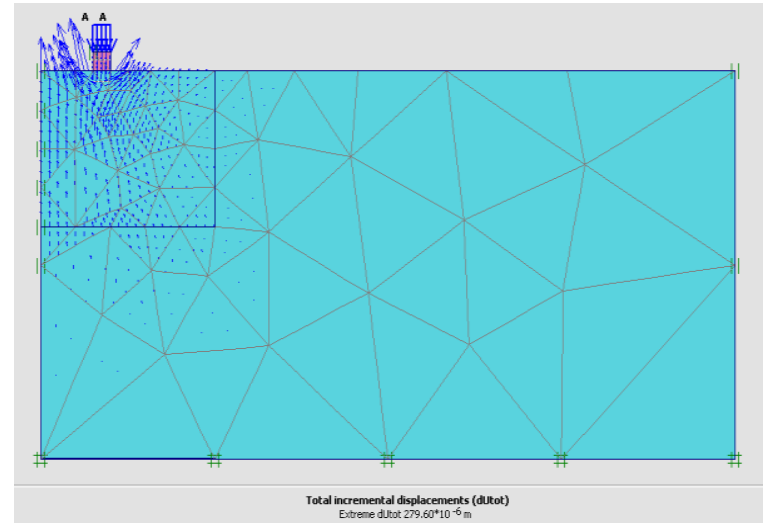

(f) $\mathrm{n}=0.75$

Fig. 11. Failure patterns for different values of radius ratio, $\varphi=40^{\circ}, r_{o}=2.0 \mathrm{~m}$.

\section{CONCLUSIONS}

The major conclusions derived from this study are as follows:

1. The radius ratio has not significant effect on the $\bar{N}_{\gamma}$ value.

2. The ultimate bearing capacity of ring footings decreases with the increase of radius ratio.

3. The failure mode of ring footings is a general shear failure and has not affected by internal friction angle of sand.

4. The value of $\bar{N}_{\gamma}$ increases with the decrease of footing size $\left(D_{o}\right)$.

5. The lateral extent ratio $\left(W / D_{o}\right)$ decreases with increasing radius ratio for different internal friction angle of sand bed.

6. The depth of failure surface $\left(d / D_{o}\right)$ under ring footings decreases with the increase of radius ratio for different internal friction angle.

\section{REFERENCES}

[1] G. G. Meyerhof, "The ultimate bearing capacity of foudations," Geotechnique, vol. 2, no. 4, pp. 301-332, 1951.

[2] K.Terzaghi, "Theoretical soil mechanics," johnwiley \& sons. New York, pp.11-15. 1943.

[3] D. V. Griffiths, "Computation of collapse loads in geomechanics by finite elements," Ingenieur-Archiv, vol. 59, no. 3 pp. 237-244, 1989.

[4] N. Manoharan, and S. P. Dasgupta, "Bearing capacity of surface footings by finite elements," Computers \& structures, vol. 54, no. 4, pp. 563-586, 1995.

[5] Hans L. Erickson and Andrew Drescher, "Bearing capacity of circular footings," Journal of geotechnical and geoenvironmental engineering, vol. 128, no. 1, pp. 38-43, 2002.

[6] Sam Frydman and Harvey J. Burd, "Numerical studies of bearing-capacity factor $N_{\gamma}$," Journal of geotechnical and geoenvironmental engineering, vol. 123, no. 1, pp. 20-29, 1997.

[7] K. E. Egorov, "Calculation of bed for foundation with ring footing," In Proc. 6 th International Conference of Soil Mechanics and Foundation Engineering, vol. 2, pp. 41-45. 1965.

[8] D. M. Milovic, "Stresses and displacements produced by a ring foundation," In Proceedings of the eighth international conference on soil mechanics and foundation engineering, Moscow, vol. 3, pp. 167-71. AA Balkema Rotterdam, The Netherlands, 1973.

[9] J. E. Bowles, "Foundation analysis and design," 5th Edition. McGraw-Hill, New York, 1997.

[10] J. H. Boushehrian, and N. Hataf, "Experimental and numerical investigation of the bearing capacity of model circular and ring footings on reinforced sand," Geotextiles and Geomembranes, vol. 21, No. 4, pp. 241-256, 2003.

[11] N. Hataf, M. Razavi, "Model tests and finite element analysis of bearing capacity of ring footings on loose sand," Iranian Journal Of Science And Technology Transaction B- Engineering, vol. 27, no. B1, 0-0, 2003.

[12] S. Saran, N. M. Bhandari, and M. M. A. Al-Smadi, "Analysis of eccentrically-obliquely loaded ring footings on sand," Indian Geotechnical Journal, vol. 33, no. 4, pp. 422-446, 2003. 
[13] J. Kumar and P. Ghosh, "Bearing capacity factor $N_{\gamma}$ for ring footings using the method of characteristics," Canadian geotechnical journal, vol. 42, no. 5, pp. 1474-1484, 2005.

[14] L. Zhao, and J. H. Wang, "Vertical bearing capacity for ring footings," Computers and Geotechnics, vol. 35, no. 2, pp. 292-304, 2008.

[15] R. B. J. Brinkgreve, "PLAXIS 2D user manual”, version 8, Balkema, Rotterdam, Netherlands, ed. 2002.

[16] M. M. Ahmed, "Stability of footings on reinforced and unreinforced sandy slopes," Ph.D.Thesis, Civil Eng. Dep., Assiut University, 2006.

[17] S. W. Sloan, and M. F. Randolph, "Numerical prediction of collapse loads using finite element methods," International Journal for Numerical and Analytical Methods in Geomechanics, vol. 6, no. 1, pp. 47-76, 1982. 